\title{
Cholecystectomy in situs inversus totalis: a laparoscopic approach
}

This article was published in the following Dove Press journal:

International Medical Case Reports Journal

27 October 2009

Number of times this article has been viewed

\section{Dan Eisenberg}

Department of Surgery, Palo Alto VA Health Care System and Stanford School of Medicine, Palo Alto, CA, USA
Correspondence: Dan Eisenberg Department of Surgery, GS I I 2, Palo Alto VA HCS, 380 I Miranda Avenue, Palo Alto, CA 94304, USA

Tel + | $650852346 \mid$

Fax +l 6508523430

Email daneisenberg@stanford.edu
Purpose: To report and describe a safe approach to laparoscopic cholecystectomy in patients with situs inversus totalis.

Methods: We present the case of a 61-year-old male who was diagnosed with gallstones and situs inversus totalis during work-up for epigastric pain. Laparoscopic cholecystectomy was performed in mirror-image to the standard approach, with the surgeon standing on the patient's right side. In order to maintain orientation and safety during the operation, anatomical structures were spatially related to each other in a "medial" and "lateral" manner, which are preserved in situs inversus; rather than "left" and "right" which are reversed.

Results: The duration of the operation was 85 minutes, which is slightly longer than our standard laparoscopic cholecystectomy. Nonetheless, the patient was discharged on the morning following surgery, which is comparable to other patients undergoing laparoscopic cholecystectomy. He was seen in follow-up on postoperative day 14 and was doing very well. There were no postoperative complications.

Conclusion: Laparoscopic cholecystectomy can be performed safely in patients with situs inversus totalis. Careful attention to unfamiliar anatomic relationships is important. Approaching the anatomy in terms of medial and lateral structures, a relationship that is preserved, is helpful to complete the procedure safely.

Keywords: cholecystectomy, laparoscopic, situs inversus, mirror-image

\section{Introduction}

First described in 1600, situs inversus totalis is a rare congenital anomaly with an autosomal recessive genetic pattern of inheritence, which is usually asymptomatic through adulthood. In the absence of rare cardiac anomalies, life expectancy is normal. ${ }^{1,2}$ Situs inversus refers to a spectrum of mirror image transpositions of the thoracic viscera, abdominal viscera, or both, and is present in approximately 1 in 5,000 to 20,000 live births. ${ }^{2}$ There is no evidence to suggest that situs inversus predisposes to cholelithiasis or that cholelithiasis occurs with greater frequency in this population. ${ }^{3}$ Similarly, symptoms of gallstone disease probably present with similar frequency as that of the general population.

Since the introduction of the technique in 1987, there have been only approximately 30 cases of laparoscopic cholecystectomy performed in patients with situs inversus reported in the literature. ${ }^{4}$ Here we report the unusual case of a patient with situs inversus totalis who presented with an episode of severe epigstric pain, and an eventual diagnosis of gallstone disease. While maintaining basic operative techniques in the dissection of the triangle of Calot, but in mirror image, laparoscopic cholecystectomy 
was performed safely, with little increase in operative time, and a postoperative course comparable to standard cholecystectomy.

\section{Case report}

The patient was a 61-year-old man with hypertension and prior hip replacement, who reported an episode of severe epigastric pain. At that time he presented to his primary care provider with nausea, although he tolerated liquids without difficulty. He was afebrile, his abdominal exam was significant for findings of epigastric tenderness, and liver function tests were abnormal. Due to a prior history of acute hepatitis, he was discharged with planned follow-up. However, because of recurrent pain, the patient underwent an abdominal ultrasound examination that revealed a left sided gallbladder and gallstones, without gallbladder wall thickening or pericholecystic fluid. No stones were seen in the bile ducts and no biliary duct dilatation was appreciated.

When seen by the surgical service, he was pain free and tolerating a low fat diet. He appeared well and was without jaundice. Abdominal exam was without tenderness or masses. Laboratory studies were normal. An electrocardiogram demonstrated findings consistent with dextrocardia, including a right axis deviation, QRS complex in lead aVR, and a negative QRS in lead I and aVL.

A computed tomography scan (Figure 1) confirmed situs inversus totalis with complete mirror image of thoracic and

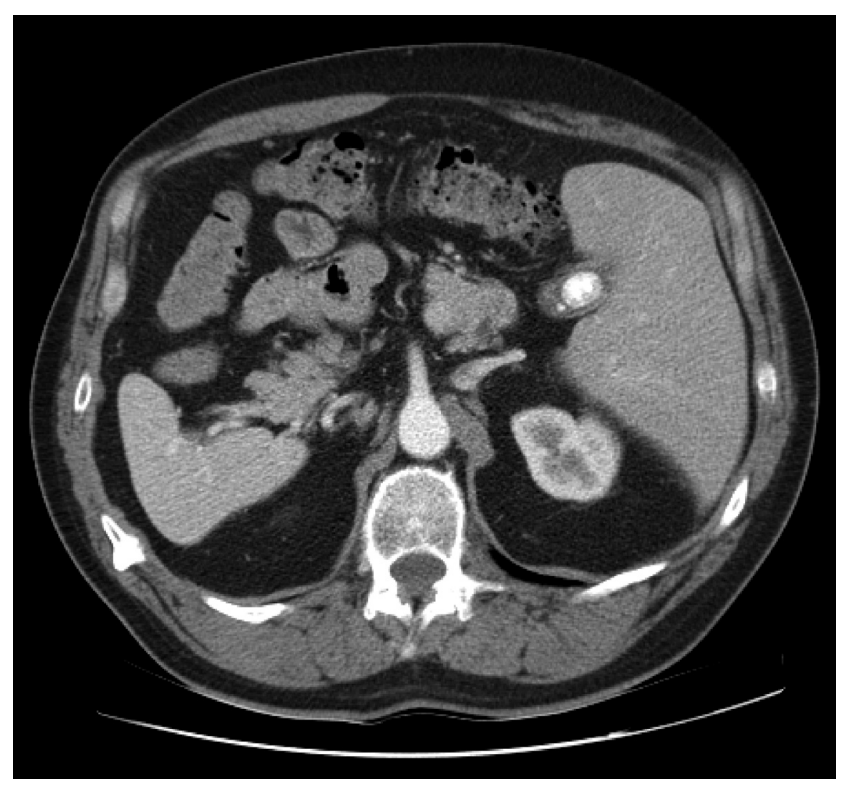

Figure I Axial computed tomography scan confirming the diagnosis of situs inversus totalis. Left-sided liver and gallbladder are seen. Gallstones also demonstrated. The spleen is seen on the right. abdominal viscera. The liver and gallbladder were in the left upper quadrant and the spleen was in the right upper quadrant. Multiple gallstones were seen in the gallbladder, and there was no evidence of intrahepatic or common bile duct dilatation.

With a diagnosis of symptomatic cholelithiasis, the patient was scheduled for an elective laparoscopic cholecystectomy. At operation, the abdomen was insufflated to a pressure of $15 \mathrm{mmHg}$ using a Veress needle that was inserted at the superior umbilical fold. A 12-mm port was inserted into the abdominal cavity, through which a 5-mm, 30 degree laparoscope was inserted and the abdomen explored. Situs inversus was confirmed with a right sided spleen and stomach, and left sided liver with a gallbladder in the left upper quadrant. A 5-mm epigastric port was inserted to the left of the falciform ligament, and two 5-mm ports were inserted along the left subcostal line.

The surgeon stood to the right of the patient, and Calot's triangle was dissected using the operator's left hand and a dissecting instrument through the epigastric port. In essence, the entire operation was performed as a mirror image of the standard laparoscopic cholecystectomy. The cystic duct and artery were clipped only after the critical view was achieved (Figure 2). The gallbladder was dissected from the liver bed using electrocautery, was placed in a bag and removed through the umbilical port. The duration of the operation was 85 minutes.

The patient tolerated the procedure well and was discharged home on postoperative day 1. Pathologic examination revealed chronic cholecystitis and cholelithiasis.

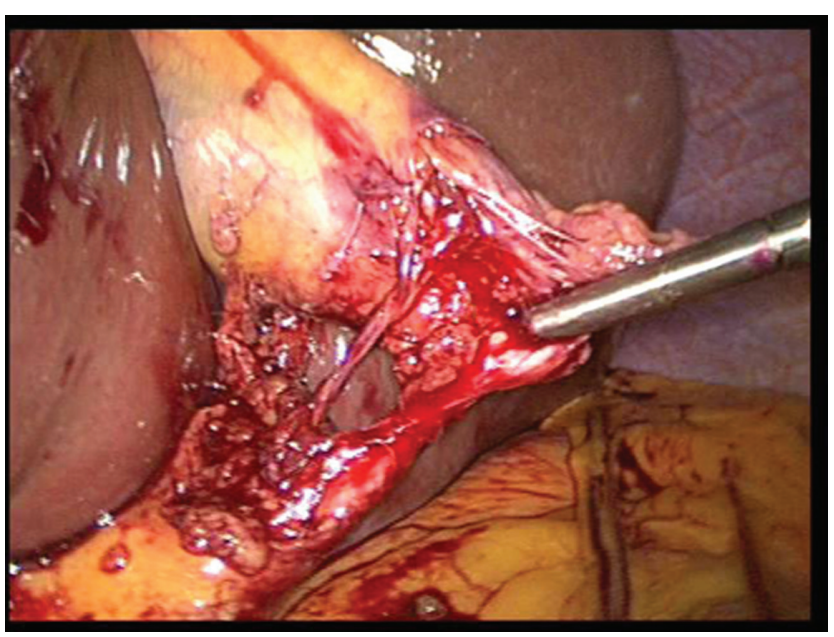

Figure 2 Intraoperative image demonstrating the critical view of safety, with single duct and single artery coursing to the left-sided gallbladder. 


\section{Discussion}

Cholecystitis in the setting of situs inversus can pose a diagnostic dilemma. ${ }^{1}$ However, with the aid of careful physical exam, electrocardiogram, and noninvasive imaging, the diagnosis of situs inversus should be made prior to laparoscopy. ${ }^{5}$ On physical exam, an apical beat in the right chest and liver percussion dullness over the left upper quadrant both suggest situs inversus. The electrocardiogram is consistent with right ventricular hypertrophy, and findings on chest X-ray, abdominal ultrasound, and computed tomography can each help secure the diagnosis.

The first case of laparoscopic cholecystectomy in a patient with situs inversus was in $1991 .{ }^{6}$ To date, only 32 additional cases had been reported. ${ }^{4}$ Here we report a case in which a patient presented with epigastric pain, but without left upper quadrant pain. Although the total number of patients is small, it is suggested that this presentation pattern is present in $30 \%$ of patients with cholecystitis and situs inversus. ${ }^{7}$ There have even been reports of patients presenting with right-sided pain alone. ${ }^{8}$ There is no clear anatomical explanation for this observation, but it may be related to incomplete inversus of the autonomic nervous system.

Although some reports suggest adjusting port placement to accommodate for a right-handed surgeon, we opted to perform the operation in complete mirror image to the conventional laparoscopic technique, as previously described. ${ }^{3,5,6}$ This requires that the entire dissection be performed with the left hand, and thus may favor the left-handed or ambidextrous surgeon. Slow and meticulous dissection at the triangle of Calot results in safe exposure of the cystic duct and artery (Figure 2). We found it helpful to approach the anatomy in terms of "medial" and "lateral" relations, rather than "left" and "right," since the medial and lateral anatomical relations in situs inversus are preserved. Strongly right-dominant surgeons have found other port arrangements to be helpful that allow the majority of the dissection to be performed with the right hand. ${ }^{7,9}$ Thus, the right-dominant surgeon can move their body to dissect the triangle of Calot using their right hand in the epigastric port, while allowing their assistant to retract Hartmann's pouch. Alternatively, the lateral ports can be moved slightly caudally and the dissecting hand can be placed in one of those ports, while the left hand retracts the gallbladder fundus through the epigastric port.

No matter which configuration is used, it is important to clearly dissect the cystic duct and artery, stay close to the inferior gallbladder edge, and obtain the critical view of safety prior to transecting any structures. This is true of all laparoscopic cholecystectomy, but especially true in this case, in which the patient's anatomic configuration is not familiar. Some surgeons may opt to selectively perform a cholangiogram to delineate ductal anatomy. ${ }^{10} \mathrm{We}$ found that following these basic principles, and continually verifying the anatomy with respect to preserved medial versus lateral relationships, allows for laparoscopic cholecystectomy to be performed safely and expediently in patients with situs inversus totalis.

\section{Acknowledgments}

The author reports no financial, pharmaceutical, or industry support in preparation of this manuscript.

\section{References}

1. Takei HT, Maxwell JG, Clancy TV, Tinsley EA. Laparoscopic cholecystectomy in situs inversus totalis. J Laparoendosc Surg. 1992;2:171-176.

2. Bohun CM, Potts JE, Casey BM, Sandor GG. A population-based study of cardiac malformations and outcomes associated with dextrocardia. Am J Cardiol. 2007;100(2):305-309.

3. Crosher RF, Harnarayan P, Bremner DN. Laparoscopic cholecystectomy in situs inversus totalis. J R Coll Edinb. 1996;41:183-184.

4. Machado NO, Chopra P. Laparoscopic cholecystectomy in a patient with situs inversus totalis: Feasibility and technical difficulties. JSLS. 2006;10:386-391.

5. Al-Jumaily M, Achab M, Hoche F. Laparoscopic cholecystectomy in situs inversus totalis: is it safe? J Laparoendosc Adv Surg Tech. 2001;11:229-231.

6. Campos L, Sipes E. Laparoscopic cholecystectomy in a 39 year old female with situs inversus. J Laparoendosc Surg. 1991;1:123-125.

7. McKay D, Blake G. Laparoscopic cholecystectomy in situs inversus totalis: a case report. BMC Surg. 2005;5:5-6.

8. Rao PG, Katariya RN, Sood S, Rao PLNG. Situs inversus totalis with calculus cholecystitis and mucinous cystadenomas of ovaries J Postgrad Med. 1977;23:89-90.

9. Goh P, Tekant Y, Shang NS, Ngoi SS. Laparoscopic cholecystectomy in a patient with empyema of the gallbladder and situs inversus. Endoscopy. 1992;24:799-800.

10. Robinson BL, Donohue JH, Gunes S, et al. Selective operative cholangiography. Appropriate management for laparoscopic cholecystectomy. Arch Surg. 1995;130:625-630.
International Medical Case Reports Journal

\section{Publish your work in this journal}

The International Medical Case Reports Journal is an international, peer-reviewed open-access journal publishing original case reports from all medical specialties. Previously unpublished medical posters are also accepted relating to any area of clinical or preclinical science. Submissions should not normally exceed 2,000 words or

\section{Dovepress}

4 published pages including figures, diagrams and references. The manuscript management system is completely online and includes a very quick and fair peer-review system, which is all easy to use. Visit http://www.dovepress.com/testimonials.php to read real quotes from published authors. 